\title{
Dealloying Behavior of NiCo and NiCoCu Thin Films
}

\author{
Benjamin E. Peecher and Jennifer R. Hampton \\ Department of Physics, Hope College, Holland, MI 49423, USA \\ Correspondence should be addressed to Jennifer R. Hampton; hampton@hope.edu
}

Received 29 July 2016; Accepted 22 September 2016

Academic Editor: Jiehua Liu

Copyright (C) 2016 B. E. Peecher and J. R. Hampton. This is an open access article distributed under the Creative Commons Attribution License, which permits unrestricted use, distribution, and reproduction in any medium, provided the original work is properly cited.

\begin{abstract}
Porous metals and alloys, such as those fabricated via electrochemical dealloying, are of interest for a variety of energy applications, ranging from their potential for enhanced catalytic behavior to their use as high surface area supports for pseudocapacitor materials. Here, the electrochemical dealloying process was explored for electrodeposited binary NiCo and ternary NiCoCu thin films. For each of the four different metal ratios, films were dealloyed using linear sweep voltammetry to various potentials in order to gain insight into the evolution of the film over the course of the linear sweep. Electrochemical capacitance, scanning electron microscopy, and energy dispersive X-ray spectroscopy were used to examine the structure and composition of each sample before and after linear sweep voltammetry was performed. For NiCo films, dealloying resulted in almost no change in composition but did result in an increased capacitance, with greater increases occurring at higher linear sweep potentials, indicating the removal of material from the films. Dealloying also resulted in the appearance of large pores on the surface of the high nickel percentage NiCo films, while low nickel percentage NiCo films had little observable change in morphology. For NiCoCu films, Cu was almost completely removed at linear sweep potentials greater than $0.5 \mathrm{~V}$ versus $\mathrm{Ag} / \mathrm{AgCl}$. The linear sweep removed large Cu-rich dendrites from the films, while also causing increases in measured capacitance.
\end{abstract}

\section{Introduction}

Porous metal structures are of increasing technological interest because of a variety of useful physical properties such as low mass density, high surface area, and high mechanical strength. These materials also have the potential for enhanced electrical, thermal, optical, or reactivity behavior, leading to a variety of possible applications [1]. For example, one significant factor for increasing the capacity and efficiency of energy storage materials is either the material itself or the scaffolding on which it is placed having a high surface area to mass ratio. Additionally, a high surface area in combination with enhanced reactivity is useful in catalysis applications.

Electrochemical dealloying of a metallic alloy is one convenient and versatile method for producing porous metals. In most cases, during this process, the less noble (more thermodynamically active) component is selectively removed from the alloy material, while the remaining component rearranges to produce the resulting porous metal $[2,3]$. This process has been used to fabricate a number of different porous metals, including $\mathrm{Au}, \mathrm{Ag}, \mathrm{Pt}, \mathrm{Pd}, \mathrm{Fe}, \mathrm{Ni}$, and $\mathrm{Cu}$ [4-16].
This more common dealloying process, however, does not always happen. The reverse process can occur if the more thermodynamically active component of an alloy is kinetically stabilized allowing the more noble component to be selectively removed instead. This atypical "reverse" dealloying behavior has been shown in $\mathrm{NiCu}$ alloys, where nickel is passivated and copper is removed $[17,18]$. The porous material produced in this way has been studied for a number of applications, including as a substrate for the subsequent deposition of a pseudocapacitor oxide material [19-26], as a scaffolding for the addition of small amounts of Pd for methanol and ethanol oxidation catalysis [27], and directly as a catalyst for the hydrogen evolution reaction $[28,29]$.

One distinctive feature of this "reverse" dealloying compared to the more common case is that atomic rearrangement during the selective removal process is not likely to occur. This rearrangement is a key component of the more common type of dealloying $[2,3]$. In contrast, the passiviation that allows the "reverse" dealloying to occur should also hinder any significant atomic movement of the component that remains. In fact, this has been observed in the $\mathrm{NiCu}$ system, 
where a phase-separated core-shell structure in the asdeposited film led to a tube-like morphology in the dealloyed material $[18,30]$. Thus, "reverse" dealloying of this type has the potential to produce a variety of final architectures based on the particular characteristics of the starting material.

The success and versatility of dealloying for binary alloys have led to the extension of the procedure for a wider range of materials, such as ternary alloys. In these cases, porous alloys can be created from the selective removal of one or more elements from the initial alloy. A number of different ternary materials, including AuPtAg, AuPtAl, AuCoAl, AuNiAl, AuPtCu, PtCoCu, PtNiAl, PtRuAl, PdCuAl, PdFeAl, and $\mathrm{CoCuAl}$, have been subjected to dealloying, with applications ranging from catalysis to sensing to energy storage [31-40]. To date, the most common element included for the purpose of selective removal is $\mathrm{Al}$. In these cases, the sacrificial component is less noble than the other components; ternary alloy cases with the potential for the "reverse" dealloying of a more noble component occurring have not been explored.

In this work, we investigate the dealloying behavior of binary $\mathrm{NiCo}$ and ternary $\mathrm{NiCoCu}$ alloys, nickel-based materials with the potential for "reverse" dealloying and for which dealloying has not been studied in depth. Thin film alloys with various compositions were electrodeposited, and linear sweep voltammetry was used to perform the dealloying for different ending potentials. The alloy thin films were characterized both before and after the dealloying procedure by measuring the electrochemical capacitance of the sample (a practical in situ measure of the accessible surface area [41]) and by determining the chemical composition with energy dispersive X-ray spectroscopy. These quantitative results were combined with scanning electron microscopy images to describe the dealloying process for these materials.

\section{Materials and Methods}

2.1. Deposition and Dealloying. NiCo and NiCoCu samples were deposited using an Epsilon electrochemical workstation (Bioanalytical Systems, Inc., West Lafayette, IN, USA) capable of performing a variety of experiments in an electrochemical cell. The metal alloy films were deposited on wafers composed of three layers: a Si substrate, a $50 \AA \mathrm{Ti}$ adhesion layer, and a $1000 \AA \mathrm{Au}$ layer (Platypus Technologies, LLC, Madison, WI, USA). These wafers were broken into roughly $5 \mathrm{~mm} \times$ $5 \mathrm{~mm}$ squares to serve as substrates for the deposited thin film samples. To perform a deposition, a wafer was placed in a custom Teflon electrochemical cell [42] with a threeelectrode system, where it served as the working electrode, a cell aperture defining its experimentally active area to be $0.032 \mathrm{~cm}^{2}$. The electrochemical cell also utilized a platinum coil (Alfa Aesar, Ward Hill, MA, USA) counter electrode and an $\mathrm{Ag} / \mathrm{AgCl}(3 \mathrm{M} \mathrm{NaCl})$ reference electrode (Bioanalytical Systems, Inc., West Lafayette, IN, USA). All potentials are reported with respect to this reference.

The electrolyte was an aqueous solution of $0.5 \mathrm{M} \mathrm{H}_{3} \mathrm{BO}_{3}$, $1 \mathrm{M} \mathrm{Na}_{2} \mathrm{SO}_{4}$, and various combinations of $\mathrm{NiSO}_{4}, \mathrm{CoSO}_{4}$, and $\mathrm{CuSO}_{4}$ such that the sum of the concentrations was constant at $0.1 \mathrm{M}$. Deposition was performed using four sets of metal alloy solutions: high nickel percentage NiCo (Set A;
$0.095 \mathrm{M} \mathrm{NiSO}_{4}$ and $0.005 \mathrm{M} \mathrm{CoSO}_{4}$ ), low nickel percentage $\mathrm{NiCo}\left(\right.$ Set B; 0.067 $\mathrm{M} \mathrm{NiSO}_{4}$ and $0.033 \mathrm{M} \mathrm{CoSO}_{4}$ ), high nickel percentage $\mathrm{NiCoCu}$ (Set C; $0.063 \mathrm{M} \mathrm{NiSO}_{4}, 0.007 \mathrm{M} \mathrm{CoSO}_{4}$, and $0.030 \mathrm{M} \mathrm{CuSO}_{4}$ ), and low nickel percentage $\mathrm{NiCoCu}$ (Set $\mathrm{D} ; 0.040 \mathrm{M} \mathrm{NiSO}_{4}, 0.030 \mathrm{M} \mathrm{CoSO}_{4}$, and 0.030 $\mathrm{M} \mathrm{CuSO}_{4}$ ). All solutions were made using $18 \mathrm{M} \Omega \cdot \mathrm{cm}$ water purified using a Barnstead Nanopure Infinity system (APS Water Services Corp., Van Nuys, CA, USA). Chemicals were purchased from Sigma-Aldrich (St. Louis, MO, USA) and used as received. For deposition, the potential was stepped from open circuit to $-1.000 \mathrm{~V}$ and held until $200 \mathrm{mC}$ of charge was deposited on the working electrode.

To dealloy the deposited thin film samples, they were returned to the electrochemical cell with a blank electrolyte, an aqueous solution of $1 \mathrm{M} \mathrm{NaSO}$, where linear sweep voltammetry (LSV) was performed starting at $0 \mathrm{~V}$, sweeping at $5 \mathrm{mV} / \mathrm{s}$, and ending at a predetermined potential from $0.300 \mathrm{~V}$ to $2.500 \mathrm{~V}$.

2.2. Characterization. Each sample was characterized by its capacitance, composition, and morphology both before and after it was dealloyed. Capacitance was measured through a series of cyclic voltammetry (CV) experiments performed with a $1 \mathrm{M} \mathrm{KOH}$ electrolyte. The potential was swept from $-0.250 \mathrm{~V}$ to $0 \mathrm{~V}$ and back to $-0.250 \mathrm{~V}$ at a variety of scan rates ranging from $25 \mathrm{mV} / \mathrm{s}$ to $400 \mathrm{mV} / \mathrm{s}$. The average $\mathrm{CV}$ current was then plotted against scan rate, from which the capacitance of the film was extracted.

The films' compositions and morphologies were measured using a TM3000 Tabletop scanning electron microscope (SEM) (Hitachi, Tokyo, Japan) with a Quantax 70 energy dispersive X-ray spectroscopy (EDS) attachment (Bruker, Madison, WI, USA). SEM images were taken of each sample at $\times 60, \times 250$, and $\times 10,000$ magnifications as qualitative measures of their morphology. The composition was measured using the EDS attachment at $\times 250$ magnification for both average composition and compositional mapping.

\section{Results and Discussion}

3.1. Deposition Results. Four sets of samples were electrodeposited, each with a different metal composition in the deposition solution. SEM imaging and EDS and electrochemical capacitance measurements were performed on each sample in order to characterize the results of the deposition step. Table 1 lists the average composition results and specific capacitance (calculated by dividing the capacitance by the geometric area of the samples) for the four sets, which are also shown in Figures 1 and 2. The specific deposition solutions for each set of samples were chosen so that comparisons in the dealloying results could be made between binary alloy NiCo samples (Sets A and B) and ternary alloy $\mathrm{NiCoCu}$ samples (Sets $C$ and D) as well as between samples with a higher percentage of $\mathrm{Ni}$ present (Sets $\mathrm{A}$ and $\mathrm{C}$ ) and those with a lower percentage of Ni present (Sets B and D). Both the composition and the capacitance displayed some variance among the nominally identically prepared samples with a given set, as indicated by the uncertainties listed in the table and the corresponding error bars in the figures which 
TABLE 1: The average as-deposited composition and specific capacitance results for all four sets of samples. The number of samples in each set, $N$, is also listed. The uncertainties listed are the standard deviations of the results, representing the spread of results in nominally identical depositions. Note that the sum of the average compositions may not add up to exactly $100 \%$ due to the averaging procedure.

\begin{tabular}{lccccc}
\hline Set & $N$ & $\mathrm{Ni}_{\text {pre }}(\%)$ & $\mathrm{Co}_{\text {pre }}(\%)$ & $\mathrm{Cu}_{\text {pre }}(\%)$ & $(C / A)_{\text {pre }}\left(\mu \mathrm{F} / \mathrm{cm}^{2}\right)$ \\
\hline $\mathrm{A}$ & 8 & $91.0 \pm 2.6$ & $9.0 \pm 2.6$ & - & $48.1 \pm 2.7$ \\
$\mathrm{~B}$ & 9 & $31.7 \pm 2.7$ & $68.3 \pm 2.7$ & - & $92 \pm 9$ \\
$\mathrm{C}$ & 8 & $61 \pm 3$ & $5.7 \pm 0.3$ & $33 \pm 3$ & $380 \pm 110$ \\
$\mathrm{D}$ & 9 & $34 \pm 4$ & $28.6 \pm 2.2$ & $38 \pm 4$ & $740 \pm 220$ \\
\hline
\end{tabular}

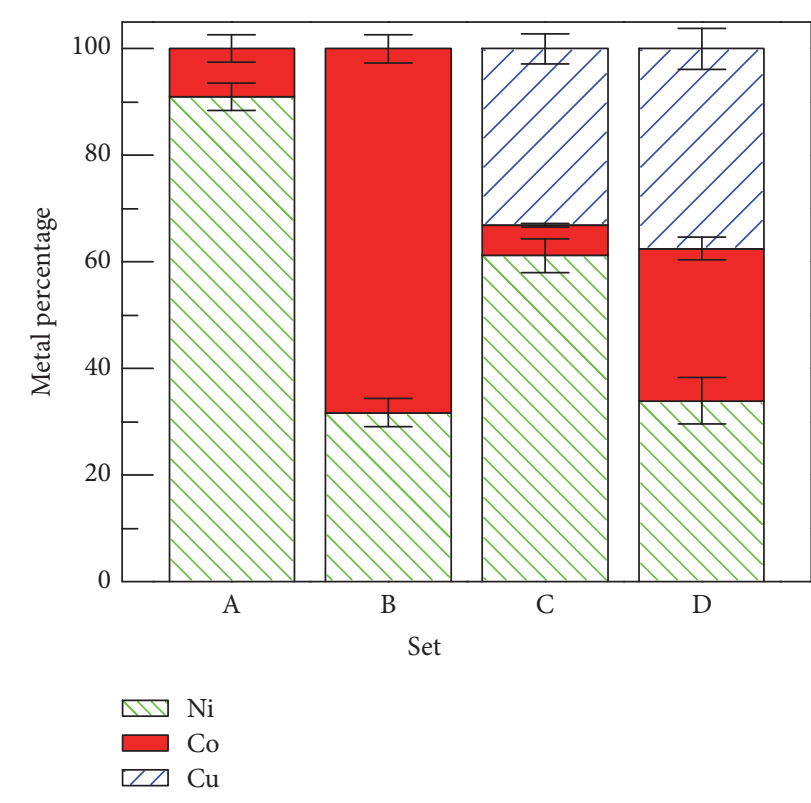

FIGURE 1: The average as-deposited compositions for all four sets of samples.

are the standard deviations of the individual results. The variations between sets, however, were generally larger than those within a given set.

The measured sample capacitance for the lower Ni percentage samples was nearly double those for the corresponding higher Ni percentage samples. More significantly, the capacitance increased by almost an order of magnitude when $\mathrm{Cu}$ was added to the film. These results can be understood qualitatively when looking at the representative SEM images of samples in each set shown in Figure 3. The samples without $\mathrm{Cu}$ have a smoother texture, while those with $\mathrm{Cu}$ show a more complex, dendritic morphology, leading to the larger capacitance measurements. The samples with the largest measured capacitance, those in Set D, had both larger and a higher density of dendrites present.

Because the dendrites are prominent features in the $\mathrm{NiCoCu}$ films, EDS mapping was performed on these samples to explore their compositions in more detail. An example EDS map is shown in Figure 4. There is some inhomogeneity in the film composition seen on the scale of the map, particularly in the $\mathrm{Cu}$ composition. Higher $\mathrm{Cu}$ composition corresponds to areas which have a higher density of dendrites.

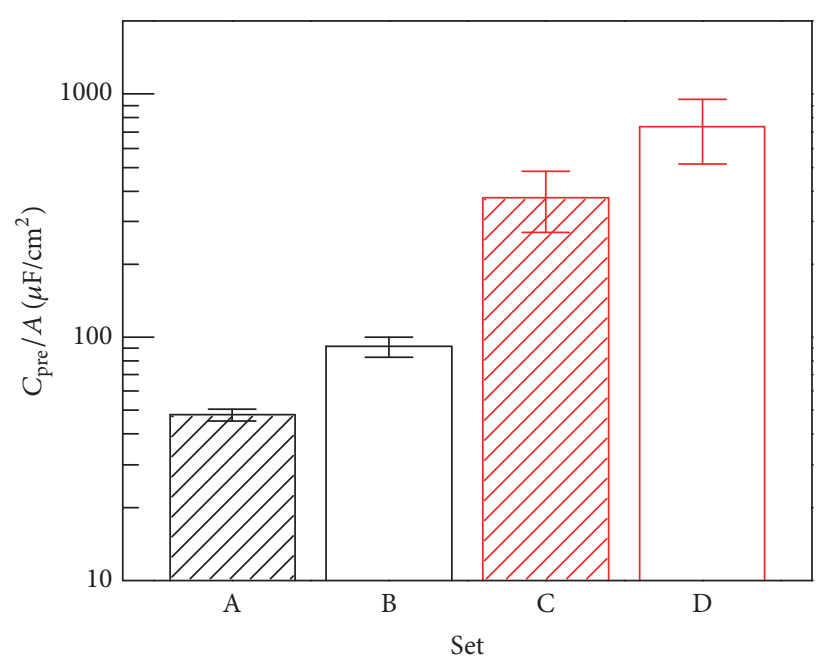

FIGURE 2: The average as-deposited specific capacitance for all four sets of samples.

3.2. Dealloying Behavior. To investigate the dealloying behavior of the alloy samples, the nominally identical samples in a given set were each subjected to LSV with varying ending potentials. In some cases, the ending potential, $E_{\mathrm{LSV}}$, was sufficiently high that the integrity of the entire thin film was compromised during the process. These samples were not included in the subsequent analysis. The NiCo samples were able to experience a higher $E_{\mathrm{LSV}}(>1.5 \mathrm{~V})$ than the $\mathrm{NiCoCu}$ samples $(\sim 1.1 \mathrm{~V})$ without being compromised. Additionally, for the binary samples, those with more $\mathrm{Ni}$ were able to experience a higher $E_{\mathrm{LSV}}(\sim 2.5 \mathrm{~V})$ than those with less $\mathrm{Ni}$ $(\sim 1.8 \mathrm{~V})$. Thus, the primary factor in structural instability for these samples was the presence of $\mathrm{Cu}$, and a smaller contributor to that instability was the presence of more Co compared to $\mathrm{Ni}$.

3.2.1. Changes in Composition. EDS measurements were performed on each of the samples after the dealloying procedure to determine whether the composition of the film changed as a result. Figure 5 shows the ratios of $\mathrm{Co}$ and $\mathrm{Cu}$ in the samples after the dealloying step to before the step as a function of $E_{\mathrm{LSV}}$ for that sample. For the NiCo samples (Sets A and B, Figure 5(a)), $\mathrm{Co}_{\text {post }} / \mathrm{Co}_{\text {pre }}$ fluctuated around 1 and did not display any clear trend with $E_{\mathrm{LSV}}$. This implies that any material that was removed during dealloying was approximately equal 
High Ni\%
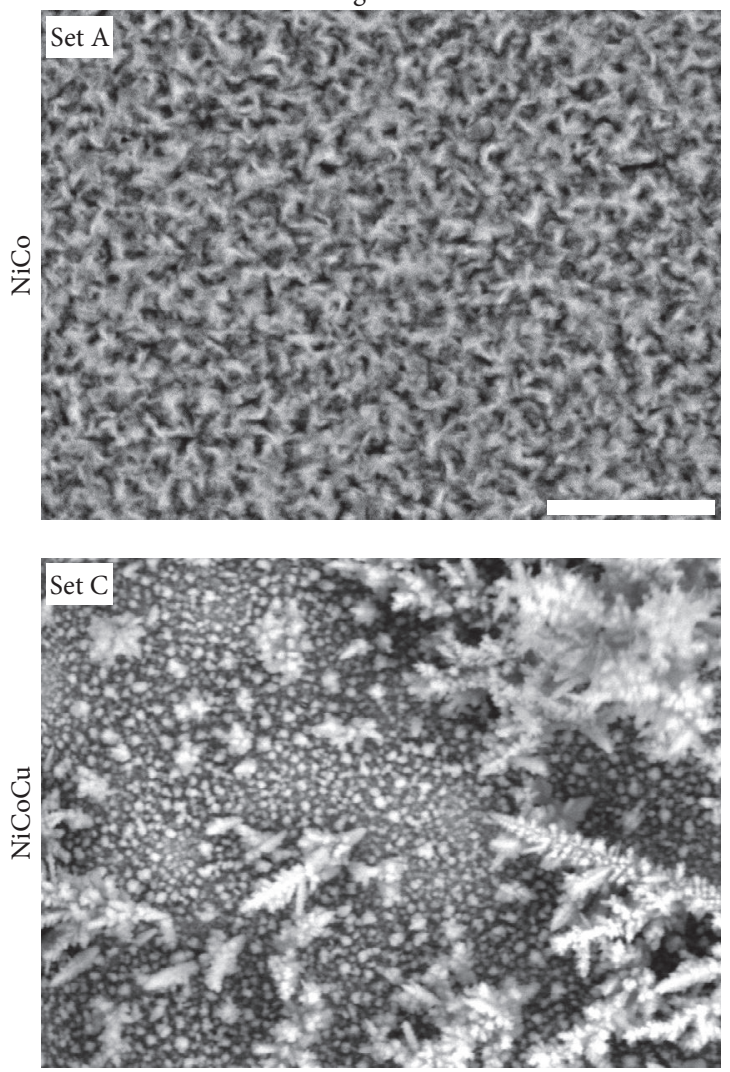

Low Ni\%
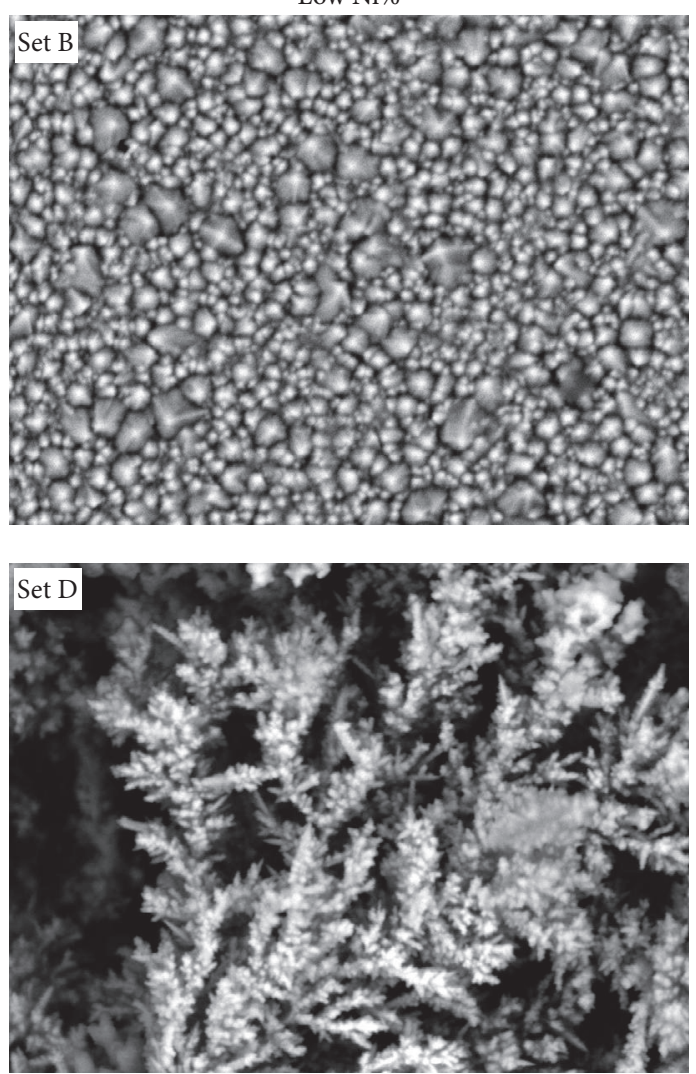

FIGURE 3: Example SEM images of samples from all four sets before the dealloying procedure. The scale bar is $5 \mu \mathrm{m}$ for all the images.
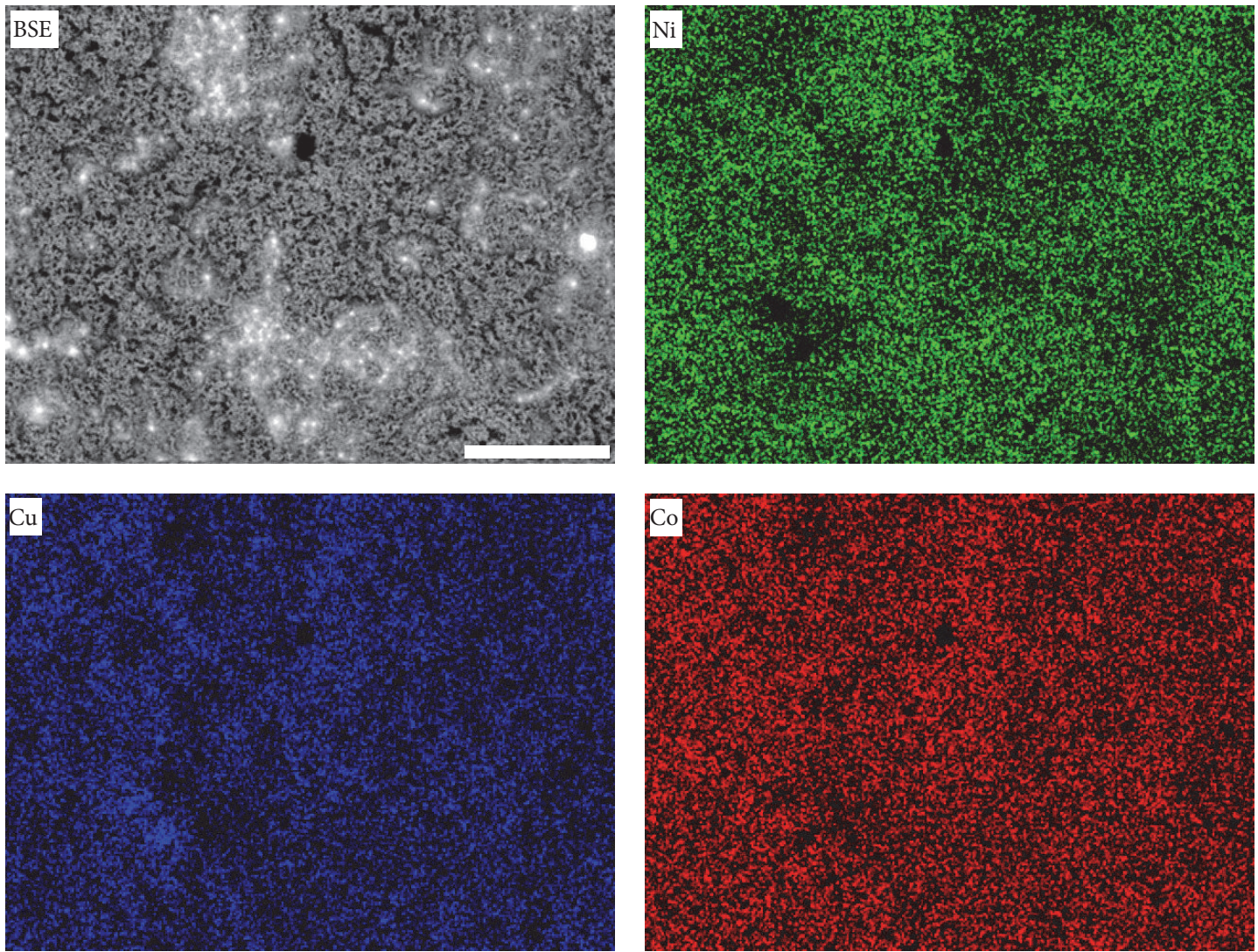

FIGURE 4: An example backscattered electron (BSE) image and EDS map of a sample from Set D. The sale bar is $200 \mu \mathrm{m}$ for all the images. 


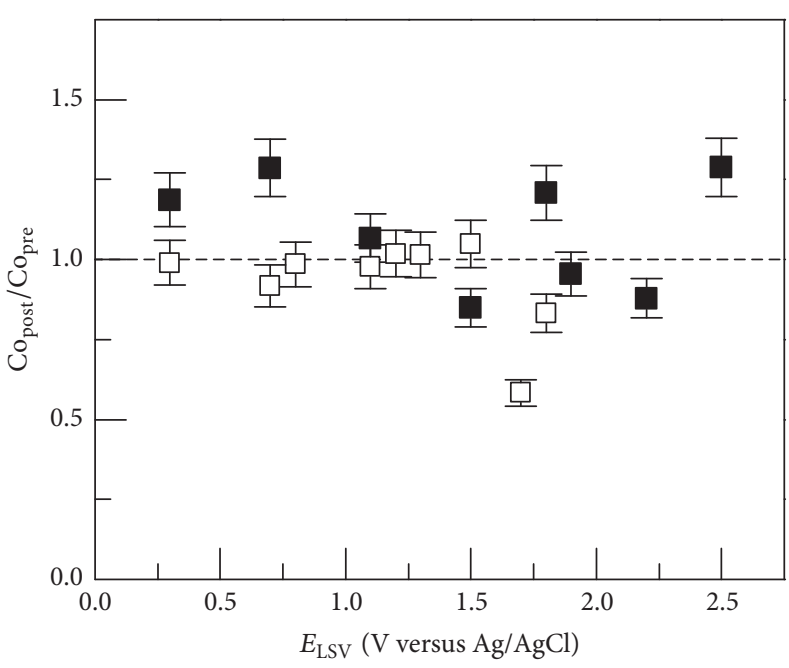

Set A Set B

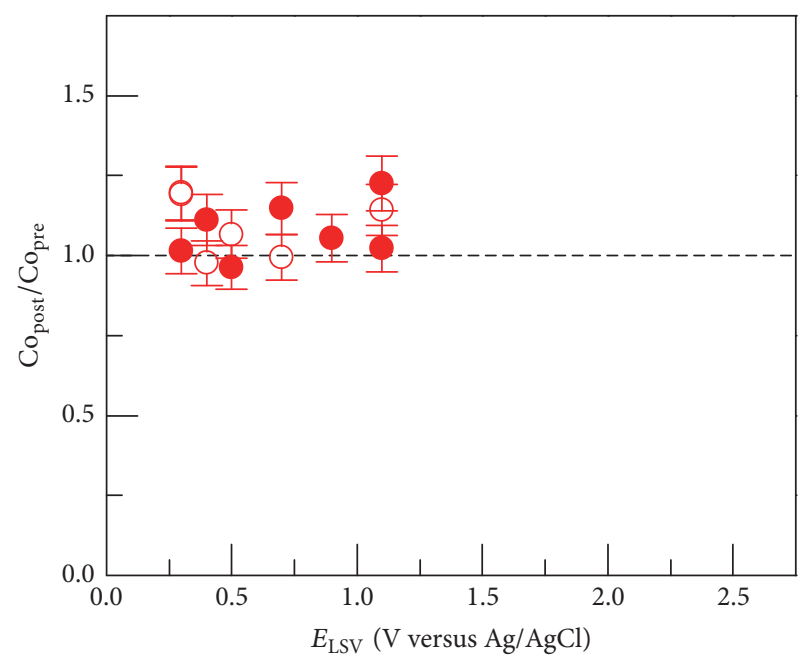

Set C

Set D

(a)

(b)

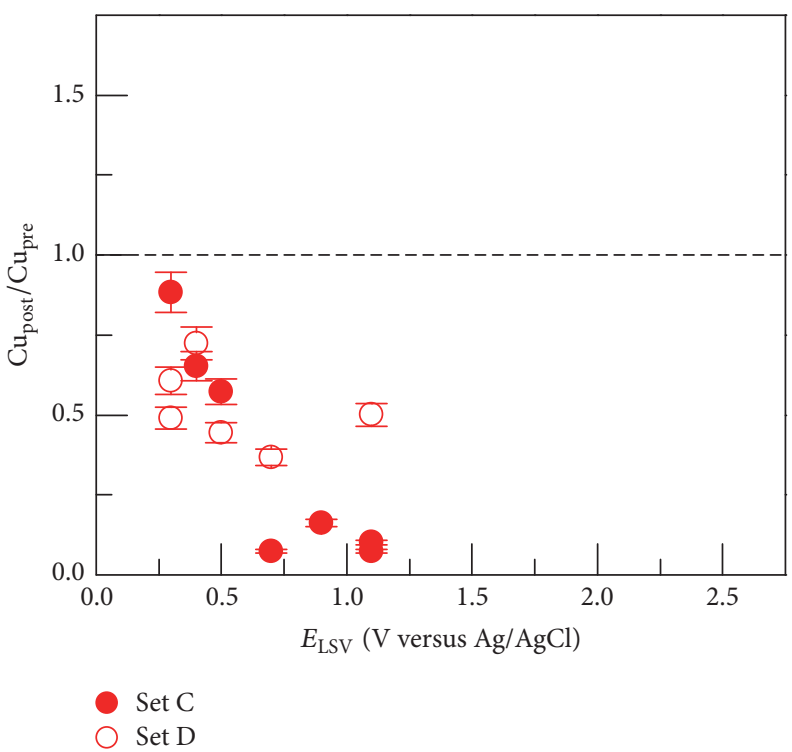

(c)

Figure 5: Elemental composition ratios, (a) $\mathrm{Co}_{\text {post }} / \mathrm{Co}_{\text {pre }}$ for the samples in Sets A and B, (b) $\mathrm{Co}_{\text {post }} / \mathrm{Co}_{\text {pre }}$ for the samples in Sets $\mathrm{C}$ and $\mathrm{D}$, and (c) $\mathrm{Cu}_{\text {post }} / \mathrm{Cu}_{\text {pre }}$ for the samples in Sets $\mathrm{C}$ and $\mathrm{D}$, as a function of $E_{\mathrm{LSV}}$. The dotted lines correspond to ratios equal to 1, indicating no change in composition for that element.

amounts of $\mathrm{Ni}$ and $\mathrm{Co}$. Similarly, $\mathrm{Co}_{\text {post }} / \mathrm{Co}_{\text {pre }}$ for the $\mathrm{NiCoCu}$ samples (Sets C and D, Figure 5(b)) was equal to or slightly above 1 , independent of $E_{\mathrm{LSV}}$. In contrast, $\mathrm{Cu}_{\text {post }} / \mathrm{Cu}_{\text {pre }}$ for the $\mathrm{NiCoCu}$ samples (Figure 5(c)) decreased significantly as $E_{\mathrm{LSV}}$ increased. The decrease in $\mathrm{Cu}$ percentage was particularly large in the high Ni percentage samples (Set C), where the $\mathrm{Cu}$ was reduced to about $10-15 \%$ of its initial value for $E_{\mathrm{LSV}}$ values larger than $0.5 \mathrm{~V}$.

3.2.2. Changes in Surface Structure. Electrochemical capacitance measurements and SEM imaging were performed on each sample after the dealloying step to characterize the structural changes to the film as a result. Figure 6 shows the ratio of the measured capacitance after the dealloying step to before that step, $C_{\text {post }} / C_{\text {pre }}$, as a function of $E_{\mathrm{LSV}}$ for that sample. Figures 7-10 show example SEM images for an as-deposited sample and three dealloyed samples with increasing $E_{\mathrm{LSV}}$ for each sample set.

For the high Ni percentage NiCo samples (Set A, Figure $6(\mathrm{a}))$, the capacitance ratio remained near 1 until $E_{\mathrm{LSV}}$ was larger than about $1.8 \mathrm{~V}$, after which it increased as $E_{\mathrm{LSV}}$ continued to increase. This is consistent with the SEM images in Figure 7, where the samples dealloyed to $E_{\mathrm{LSV}}=0.7 \mathrm{~V}$ and $1.5 \mathrm{~V}$ are very similar to the as-deposited sample, but that dealloyed to $E_{\mathrm{LSV}}=2.5 \mathrm{~V}$ has a large number of pores where 


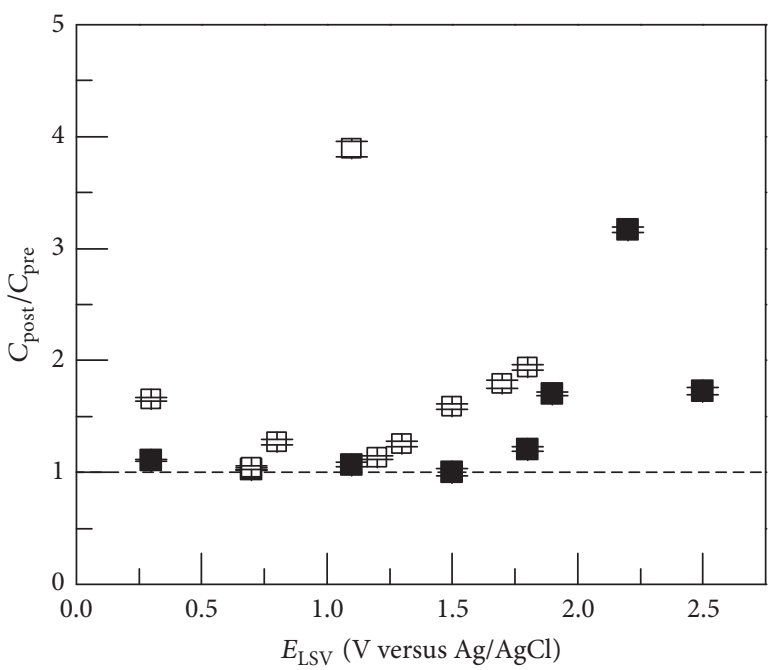

- Set A

$\square$ Set B

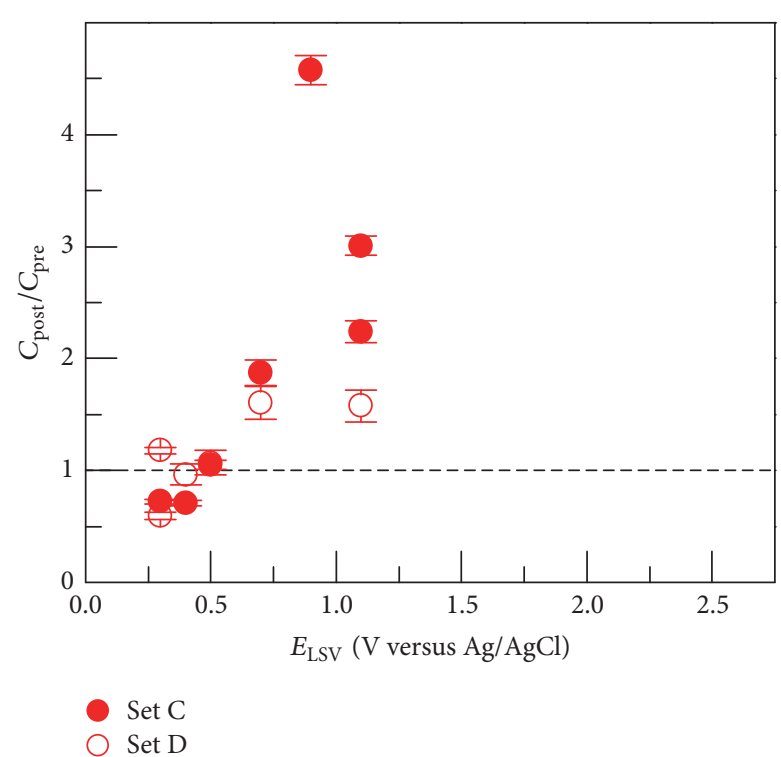

(b)

Figure 6: Capacitance ratios, $C_{\text {post }} / C_{\text {pre }}$, for (a) the samples in Sets A and B and (b) the samples in Sets C and D as a function of $E_{\mathrm{LSV}}$. The dotted lines correspond to ratios equal to 1 , indicating no change in capacitance.
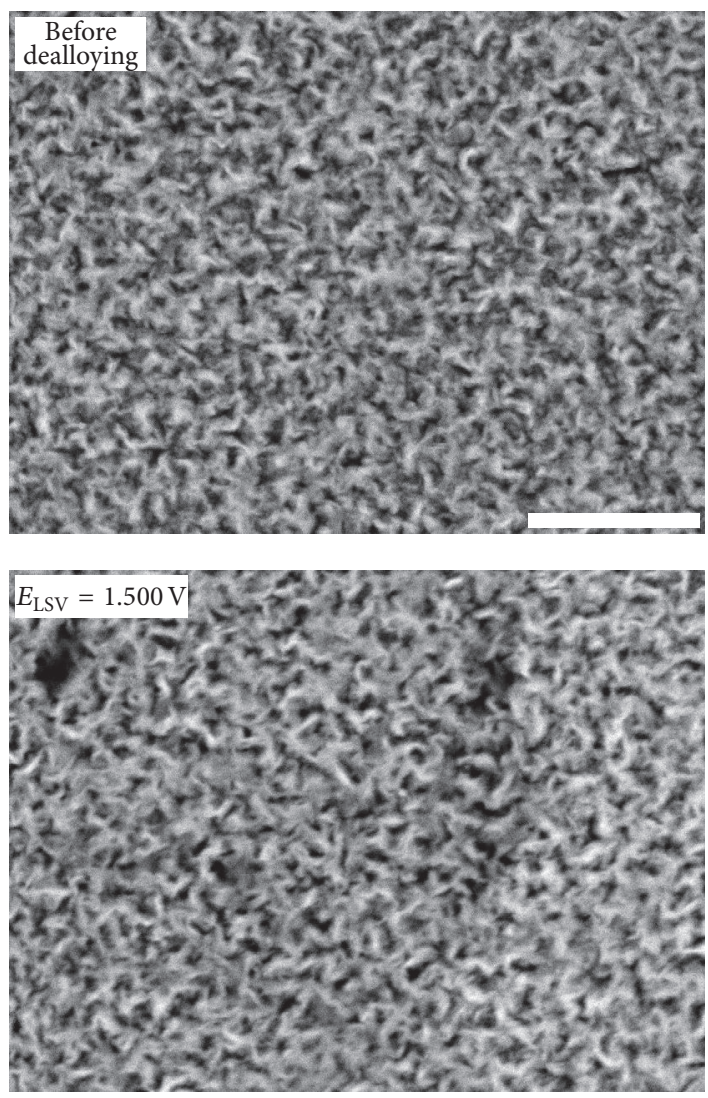
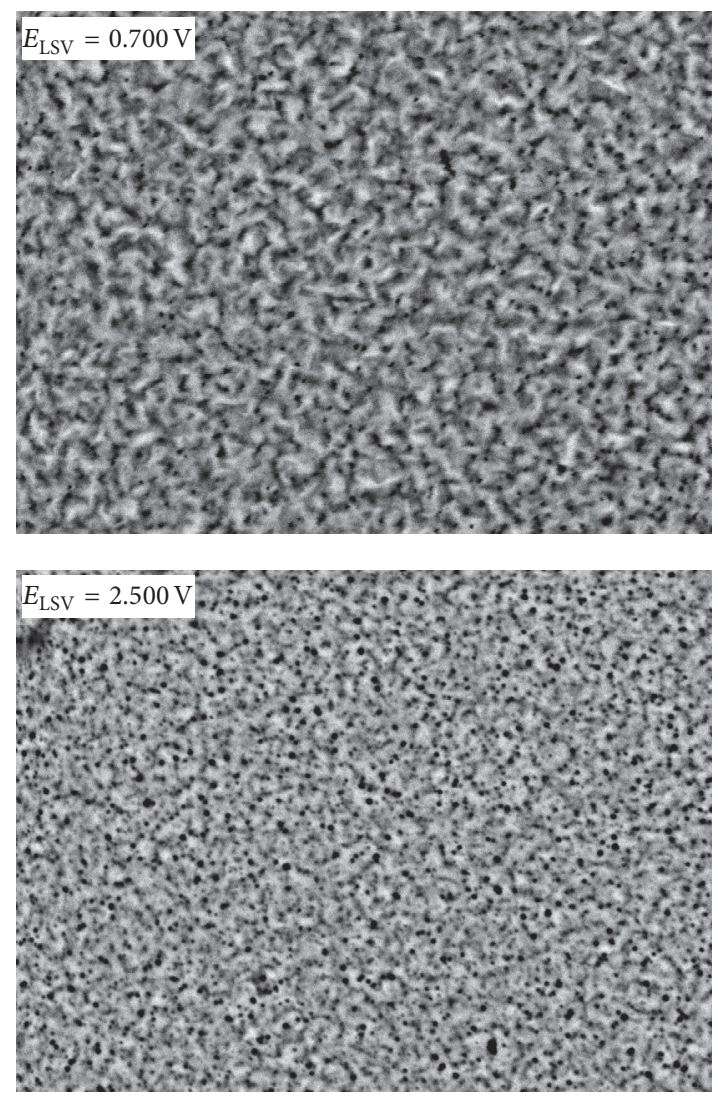

FIGURE 7: SEM images of samples from the high Ni percentage NiCo samples (Set A) before dealloying and after different dealloying steps. The scale bar is $5 \mu \mathrm{m}$ for all the images. 

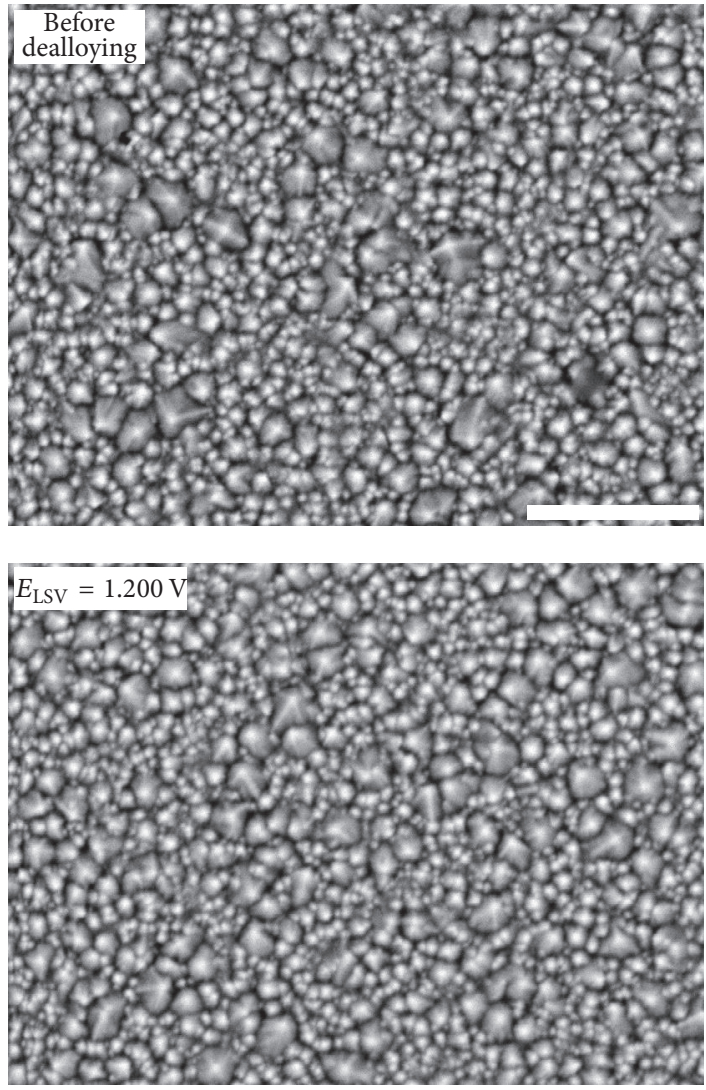
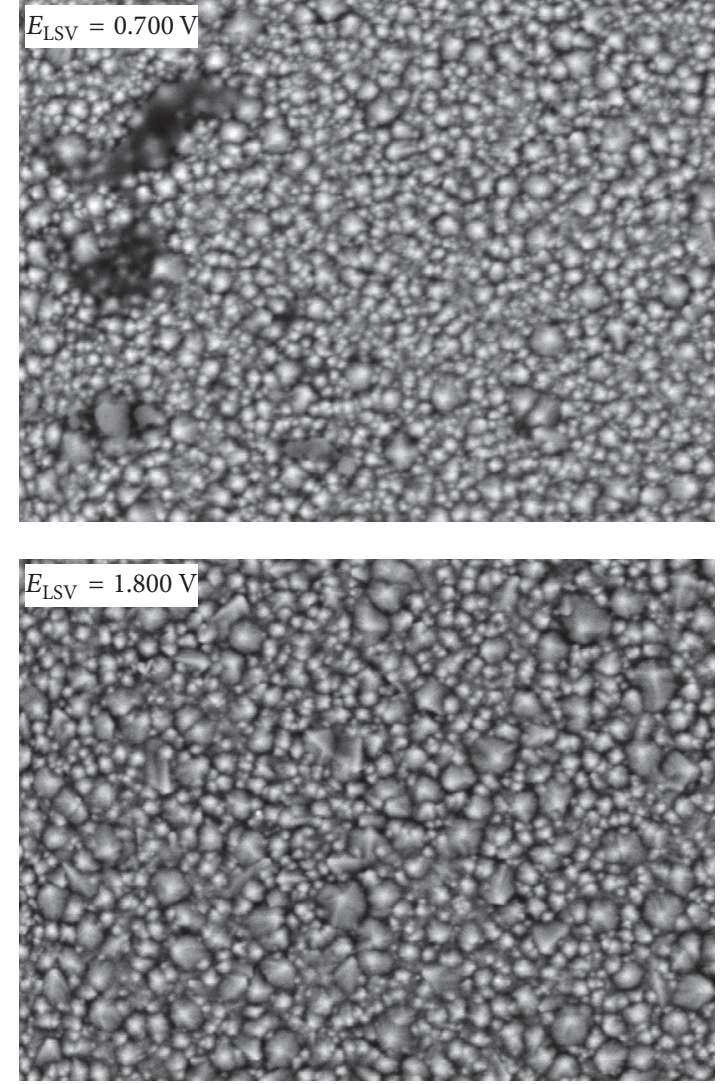

FIGURE 8: SEM images of samples from the low Ni percentage NiCo samples (Set B) before dealloying and after different dealloying steps. The scale bar is $5 \mu \mathrm{m}$ for all the images.
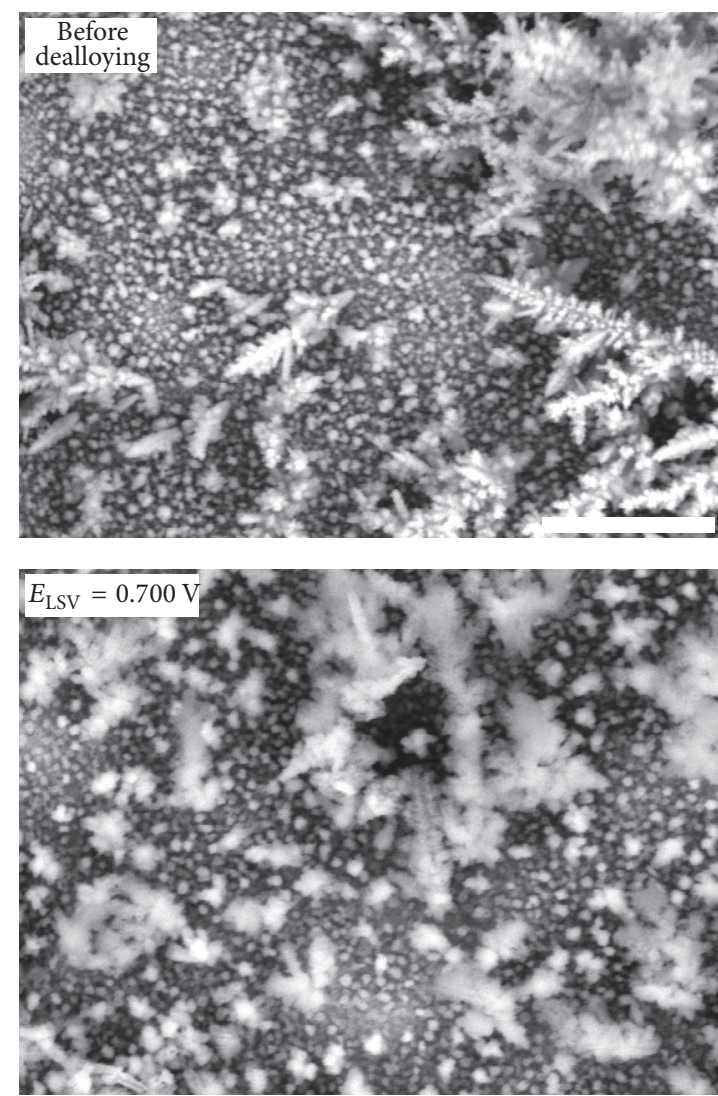
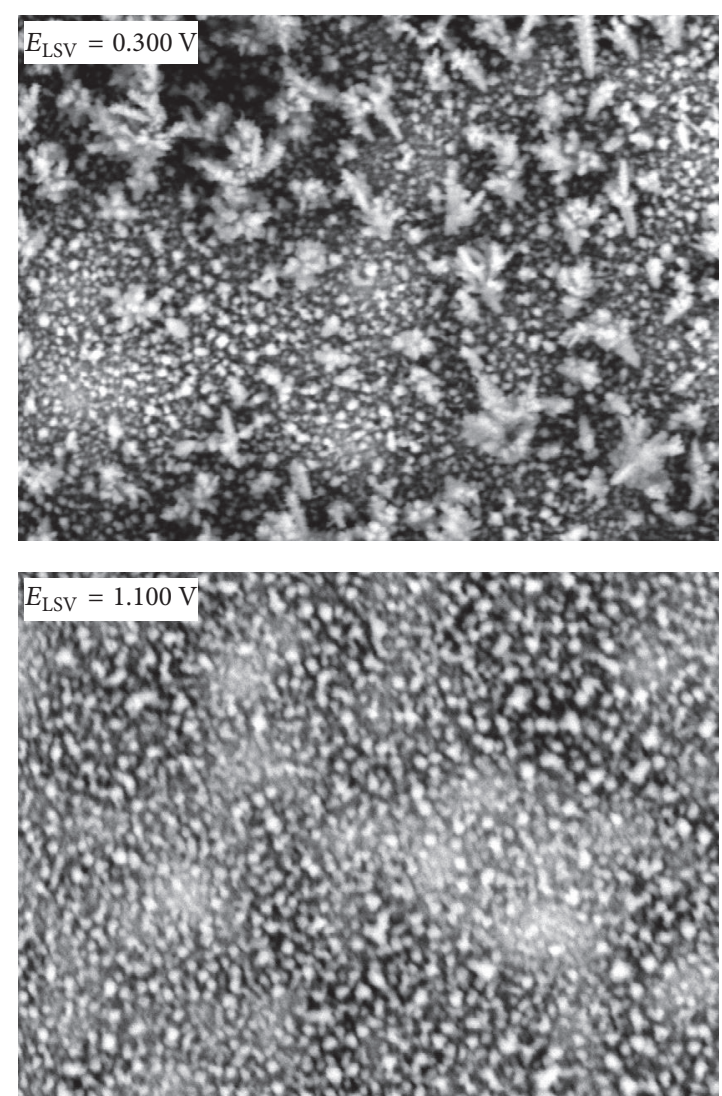

FigurE 9: SEM images of samples from the high Ni percentage $\mathrm{NiCoCu}$ samples (Set C) before dealloying and after different dealloying steps. The scale bar is $5 \mu \mathrm{m}$ for all the images. 

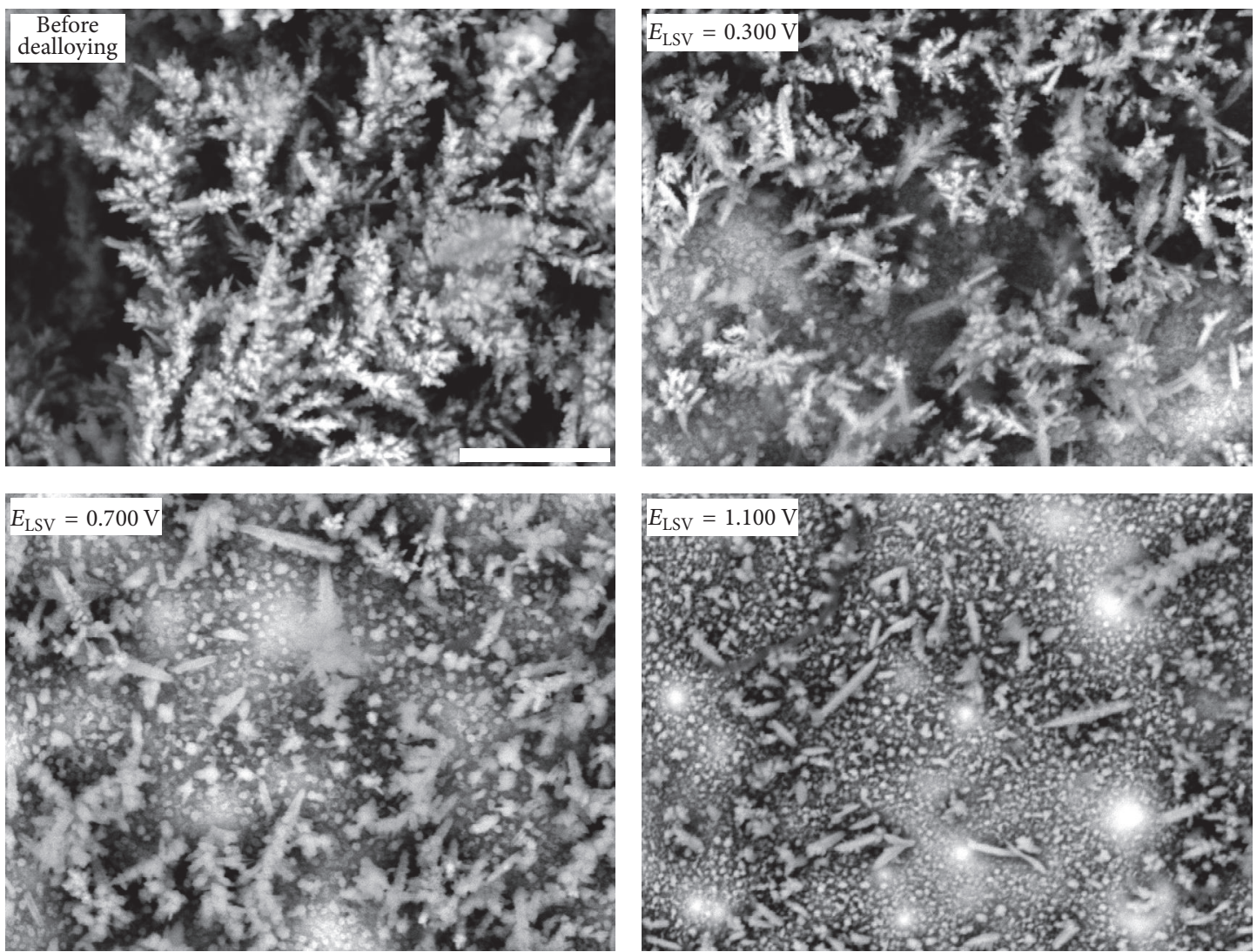

FIGURE 10: SEM images of samples from the low Ni percentage NiCoCu samples (Set D) before dealloying and after different dealloying steps. The scale bar is $5 \mu \mathrm{m}$ for all the images.

material has been removed, increasing the surface area of the film.

In the low $\mathrm{Ni}$ percentage $\mathrm{NiCo}$ samples (Set $\mathrm{B}$, Figure $6(\mathrm{a})$ ), the capacitance ratio also generally increased as $E_{\mathrm{LSV}}$ increased. The SEM images in Figure 8 show relatively similar morphology regardless of the $E_{\mathrm{LSV}}$ value. Thus, the increase in capacitance is likely due to changes in morphology around the numerous grain boundaries in the film or smaller features not resolvable at the scale used for imaging.

Similar to the NiCo samples, the $\mathrm{NiCoCu}$ samples (Sets $\mathrm{C}$ and D, Figure 6(b)) have capacitance ratios that generally increase as $E_{\mathrm{LSV}}$ increases. However, these capacitance ratios are lower than 1 for small values of $E_{\mathrm{LSV}}$ (less than $\sim 0.5 \mathrm{~V}$ ), indicating a decrease in surface area compared to the asdeposited films. This is consistent with the SEM images in Figures 9 and 10, where the size and density of the dendritic structures decreased during the dealloying step. The subsequent increase in capacitance ratio above 1, however, implies that, after smoothening due to loss of dendrites, the surface area again increases. Some smaller features due to additional material being removed can be seen in the SEM images for high $E_{\mathrm{LSV}}$ values; but the increase in measured capacitance above the as-deposited values, particularly in the high Ni percentage samples (Set C), implies that many smaller features are likely present in the dealloyed films.

\section{Conclusions}

For the binary NiCo combinations studied here, the results indicate that $\mathrm{Ni}$ is a stabilizing agent for $\mathrm{Co}$ in the film. Material is removed from NiCo films as a result of the dealloying procedure, as indicated by SEM images and increased capacitance measurements; however this occurs only at relatively high linear sweep potentials, and in these cases, $\mathrm{Ni}$ and $\mathrm{Co}$ are removed in approximately equal amounts. These results are distinct from those for $\mathrm{NiCu}$ films where "reverse" dealloying occurs and $\mathrm{Cu}$ is selectively removed $[17,18]$. Additionally, the higher the Ni percentage in the film, the higher the linear sweep potential that the sample can experience without becoming structurally unsound.

For the ternary NiCoCu combinations studied, "reverse" dealloying does occur and $\mathrm{Cu}$ is selectively removed from the films. In these cases, Co is still stabilized by the presence of $\mathrm{Ni}$ and is not selectively removed, just as in the binary NiCo samples. For the ternary films, linear sweep voltammetry first removes many of the $\mathrm{Cu}$-rich dendrites, decreasing the measured capacitance, and then removes material from the bulk of the film, increasing the capacitance. Additionally, the presence of $\mathrm{Cu}$ in the film decreases the maximum linear sweep potential that the sample can experience before its structural integrity is compromised. 
These observations are consistent with the behavior seen for other "reverse" dealloying combinations. The stabilization of $\mathrm{Ni}$ and $\mathrm{Co}$ in the thin film allows $\mathrm{Cu}$ to be selectively removed. The material that remains does not significantly rearrange; instead, the $\mathrm{Cu}$-rich parts of the original morphology, such as the dendrites in the ternary films, are those which are most easily removed. At the same time, if there is too much $\mathrm{Cu}$ in the initial material, its removal may result in the film itself becoming structurally compromised, particularly when dealloying to a higher potential.

Future work planned in our lab aims to explore the dealloying behavior for these nickel-based alloys further, particularly for cases with similar film compositions but distinct sample morphologies, such as reduced or eliminated dendritic structures. These dealloyed nickel-based alloys can also be used as scaffolds for the subsequent deposition of electroactive compounds such as the Prussian Blue analogues, resulting in innovative architecture for energy storage applications.

\section{Competing Interests}

The authors declare that there is no conflict of interest regarding the publication of this paper.

\section{Acknowledgments}

This work is supported by the United States National Science Foundation under Grant nos. RUI-DMR-1104725, MRICHE-0959282, and ARI-PHY-0963317, by an award to Hope College from the Howard Hughes Medical Institute through the Undergraduate Science Education Program, and by the Hope College Department of Physics.

\section{References}

[1] C. T. Bryce, A. S. Stephen III, and E. P. Luther, "Nanoporous metal foams," Angewandte Chemie-International Edition, vol. 49, no. 27, pp. 4544-4565, 2010.

[2] J. Erlebacher, M. J. Aziz, A. Karma, N. Dimitrov, and K. Sieradzki, "Evolution of nanoporosity in dealloying," Nature, vol. 410, no. 6827, pp. 450-453, 2001.

[3] J. Erlebacher, "An atomistic description of dealloying: porosity evolution, the critical potential, and rate-limiting behavior," Journal of the Electrochemical Society, vol. 151, no. 10, pp. C614C626, 2004.

[4] Y. Ding and J. Erlebacher, "Nanoporous metals with controlled multimodal pore size distribution," Journal of the American Chemical Society, vol. 125, no. 26, pp. 7772-7773, 2003.

[5] K. Brunelli, M. Dabalà, R. Frattini, and M. Magrini, "Structural characterization and electrocatalytic properties of $\mathrm{Au}_{30} \mathrm{Zr}_{70}$ amorphous alloy obtained by rapid quenching," Journal of Applied Electrochemistry, vol. 33, no. 11, pp. 995-1000, 2003.

[6] F. Jia, C. Yu, K. Deng, and L. Zhang, "Nanoporous metal (Cu, $\mathrm{Ag}, \mathrm{Au}$ ) films with high surface area: general fabrication and preliminary electrochemical performance," Journal of Physical Chemistry C, vol. 111, no. 24, pp. 8424-8431, 2007.
[7] F. Jia, C. Yu, Z. Ai, and L. Zhang, "Fabrication of nanoporous gold film electrodes with ultrahigh surface area and electrochemical activity," Chemistry of Materials, vol. 19, no. 15, pp. 3648-3653, 2007.

[8] A. Jaron and Z. Żurek, "New porous iron electrode for hydrogen evolution-production and properties," Archives of Metallurgy and Materials, vol. 53, no. 3, pp. 847-853, 2008.

[9] J. Snyder, K. Livi, and J. Erlebacher, "Dealloying silver/gold alloys in neutral silver nitrate solution: porosity evolution, surface composition, and surface oxides," Journal of the Electrochemical Society, vol. 155, no. 8, pp. C464-C473, 2008.

[10] L.-Y. Chen, J.-S. Yu, T. Fujita, and M.-W. Chen, "Nanoporous copper with tunable nanoporosity for SERS applications," Advanced Functional Materials, vol. 19, no. 8, pp. 1221-1226, 2009.

[11] M. Hakamada, M. Takahashi, T. Furukawa, and M. Mabuchi, "Coercivity of nanoporous Ni produced by dealloying," Applied Physics Letters, vol. 94, no. 15, Article ID 153105, 2009.

[12] X. Wang, Z. Qi, C. Zhao, W. Wang, and Z. Zhang, "Influence of alloy composition and dealloying solution on the formation and microstructure of monolithic nanoporous silver through chemical dealloying of Al-Ag alloys," The Journal of Physical Chemistry C, vol. 113, no. 30, pp. 13139-13150, 2009.

[13] A. Antoniou, D. Bhattacharrya, J. K. Baldwin et al., "Controlled nanoporous Pt morphologies by varying deposition parameters," Applied Physics Letters, vol. 95, no. 7, Article ID 073116, 2009.

[14] S. Sattayasamitsathit, P. Thavarungkul, C. Thammakhet et al., "Fabrication of nanoporous copper film for electrochemical detection of glucose," Electroanalysis, vol. 21, no. 21, pp. 23712377, 2009.

[15] M. Hakamada, H. Nakano, T. Furukawa, M. Takahashi, and M. Mabuchi, "Hydrogen storage properties of nanoporous palladium fabricated by dealloying," Journal of Physical Chemistry C, vol. 114, no. 2, pp. 868-873, 2010.

[16] Q. Zhang and Z. Zhang, "On the electrochemical dealloying of Al-based alloys in a $\mathrm{NaCl}$ aqueous solution," Physical Chemistry Chemical Physics, vol. 12, no. 7, pp. 1453-1472, 2010.

[17] L. Sun, C.-L. Chien, and P. C. Searson, "Fabrication of nanoporous nickel by electrochemical dealloying," Chemistry of Materials, vol. 16, no. 16, pp. 3125-3129, 2004.

[18] J.-K. Chang, S.-N. Hsu, I.-W. Sun, and W.-T. Tsai, “Formation of nanoporous nickel by selective anodic etching of the nobler copper component from electrodeposited nickel-copper alloys," Journal of Physical Chemistry C, vol. 112, no. 5, pp. 1371-1376, 2008.

[19] J.-K. Chang, S.-H. Hsu, W.-T. Tsai, and I.-W. Sun, "A novel electrochemical process to prepare a high-porosity manganese oxide electrode with promising pseudocapacitive performance," Journal of Power Sources, vol. 177, no. 2, pp. 676-680, 2008.

[20] M.-J. Deng, F.-L. Huang, I.-W. Sun, W.-T. Tsai, and J.-K. Chang, "An entirely electrochemical preparation of a nanostructured cobalt oxide electrode with superior redox activity," Nanotechnology, vol. 20, no. 17, Article ID 175602, 2009.

[21] J.-K. Chang, C.-M. Wu, and I.-W. Sun, "Nano-architectured $\mathrm{Co}(\mathrm{OH})_{2}$ electrodes constructed using an easily-manipulated electrochemical protocol for high-performance energy storage applications," Journal of Materials Chemistry, vol. 20, no. 18, pp. 3729-3735, 2010.

[22] D.-S. Kong, J.-M. Wang, H.-B. Shao, J.-Q. Zhang, and C.-N. Cao, "Electrochemical fabrication of a porous nanostructured 
nickel hydroxide film electrode with superior pseudocapacitive performance," Journal of Alloys and Compounds, vol. 509, no. 18, pp. 5611-5616, 2011.

[23] C.-M. Wu, C.-Y. Fan, I.-W. Sun, W.-T. Tsai, and J.-K. Chang, "Improved pseudocapacitive performance and cycle life of cobalt hydroxide on an electrochemically derived nano-porous Ni framework," Journal of Power Sources, vol. 196, no. 18, pp. 7828-7834, 2011.

[24] M.-G. Jeong, K. Zhuo, S. Cherevko, and C.-H. Chung, "Formation of nanoporous nickel oxides for supercapacitors prepared by electrodeposition with hydrogen evolution reaction and electrochemical dealloying," Korean Journal of Chemical Engineering, vol. 29, no. 12, pp. 1802-1805, 2012.

[25] X. Dai, D. Chen, H. Fan et al., "Ni(OH)2/NiO/Ni composite nanotube arrays for high-performance supercapacitors," Electrochimica Acta, vol. 154, pp. 128-135, 2015.

[26] M.-J. Deng, C.-Z. Song, C.-C. Wang, Y.-C. Tseng, J.-M. Chen, and K.-T. Lu, "Low cost facile synthesis of large-area cobalt hydroxide nanorods with remarkable pseudocapacitance," ACS Applied Materials and Interfaces, vol. 7, no. 17, pp. 9147-9156, 2015.

[27] T. G. Nikiforova, T. V. Savel'Eva, and O. A. Datskevich, "Catalytic activity of electrolytic palladium deposits on porous nickel substrates," Russian Journal of Applied Chemistry, vol. 84, no. 8, pp. 1347-1353, 2011.

[28] K. R. Koboski, E. F. Nelsen, and J. R. Hampton, "Hydrogen evolution reaction measurements of dealloyed porous $\mathrm{NiCu}$," Nanoscale Research Letters, vol. 8, no. 1, article 528, 2013.

[29] Z. Yin and F. Chen, "Electrochemically fabricated hierarchical porous $\mathrm{Ni}(\mathrm{OH})_{2} / \mathrm{NiCu}$ electrodes for hydrogen evolution reaction," Electrochimica Acta, vol. 117, pp. 84-91, 2014.

[30] Z. Liu, G. Xia, F. Zhu et al., "Exploiting finite size effects in a novel core/shell microstructure," Journal of Applied Physics, vol. 103, no. 6, Article ID 064313, 2008.

[31] J. Snyder, P. Asanithi, A. B. Dalton, and J. Erlebacher, "Stabilized nanoporous metals by dealloying ternary alloy precursors," Advanced Materials, vol. 20, no. 24, pp. 4883-4886, 2008.

[32] K. C. Neyerlin, R. Srivastava, C. Yu, and P. Strasser, "Electrochemical activity and stability of dealloyed $\mathrm{Pt}-\mathrm{Cu}$ and $\mathrm{Pt}-\mathrm{Cu}-$ Co electrocatalysts for the oxygen reduction reaction (ORR)," Journal of Power Sources, vol. 186, no. 2, pp. 261-267, 2009.

[33] C. Xu, R. Wang, M. Chen, Y. Zhang, and Y. Ding, "Dealloying to nanoporous $\mathrm{Au} / \mathrm{Pt}$ alloys and their structure sensitive electrocatalytic properties," Physical Chemistry Chemical Physics, vol. 12, no. 1, pp. 239-246, 2010.

[34] C. Xu, L. Wang, X. Mu, and Y. Ding, "Nanoporous PtRu alloys for electrocatalysis," Langmuir, vol. 26, no. 10, pp. 7437-7443, 2010.

[35] Z. Zhang, Y. Wang, and X. Wang, "Nanoporous bimetallic Pt-Au alloy nanocomposites with superior catalytic activity towards electro-oxidation of methanol and formic acid," Nanoscale, vol. 3, no. 4, pp. 1663-1674, 2011.

[36] R. Wang, C. Xu, X. Bi, and Y. Ding, "Nanoporous surface alloys as highly active and durable oxygen reduction reaction electrocatalysts," Energy and Environmental Science, vol. 5, no. 1, pp. 5281-5286, 2012.

[37] C. Xu, Y. Liu, J. Wang, H. Geng, and H. Qiu, "Nanoporous $\mathrm{PdCu}$ alloy for formic acid electro-oxidation," Journal of Power Sources, vol. 199, pp. 124-131, 2012.
[38] Z. Zhang, C. Zhang, Y. Gao, J. Frenzel, J. Sun, and G. Eggeler, "Dealloying strategy to fabricate ultrafine nanoporous goldbased alloys with high structural stability and tunable magnetic properties," CrystEngComm, vol. 14, no. 23, pp. 8292-8300, 2012.

[39] J. Wang, Z. Wang, D. Zhao, and C. Xu, "Facile fabrication of nanoporous PdFe alloy for nonenzymatic electrochemical sensing of hydrogen peroxide and glucose," Analytica Chimica Acta, vol. 832, pp. 34-43, 2014.

[40] Q. Hao, D. Zhao, H. Duan, and C. Xu, "Porous $\mathrm{Co}_{3} \mathrm{O}_{4} / \mathrm{CuO}$ composite assembled from nanosheets as high-performance anodes for lithium-ion batteries," ChemSusChem, vol. 8, no. 8, pp. 1435-1441, 2015.

[41] M. J. Gira, K. P. Tkacz, and J. R. Hampton, "Physical and electrochemical area determination of electrodeposited $\mathrm{Ni}, \mathrm{Co}$, and NiCo thin films," Nano Convergence, vol. 3, article 6, 2016.

[42] N. R. Wozniak, A. A. Frey, L. W. Osterbur, T. S. Boman, and J. R. Hampton, "An electrochemical cell for the efficient turn around of wafer working electrodes," Review of Scientific Instruments, vol. 81, no. 3, Article ID 034102, 2010. 

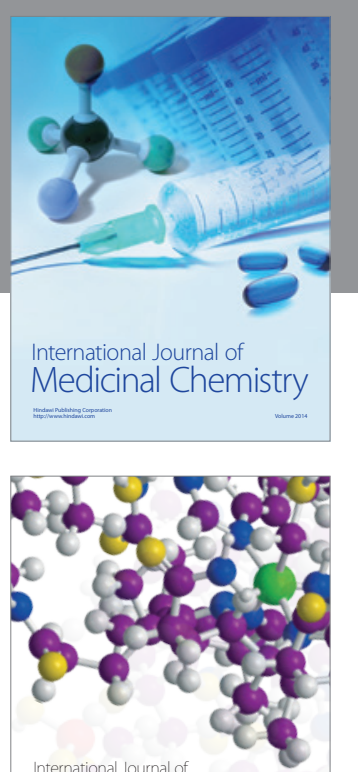

Carbohydrate Chemistry

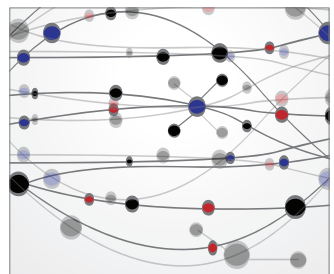

The Scientific World Journal
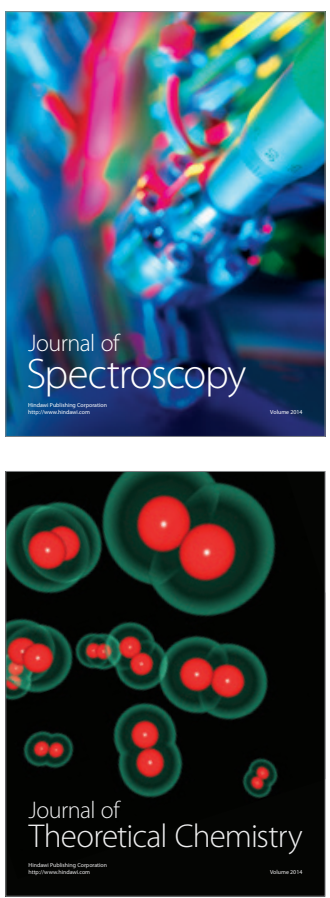
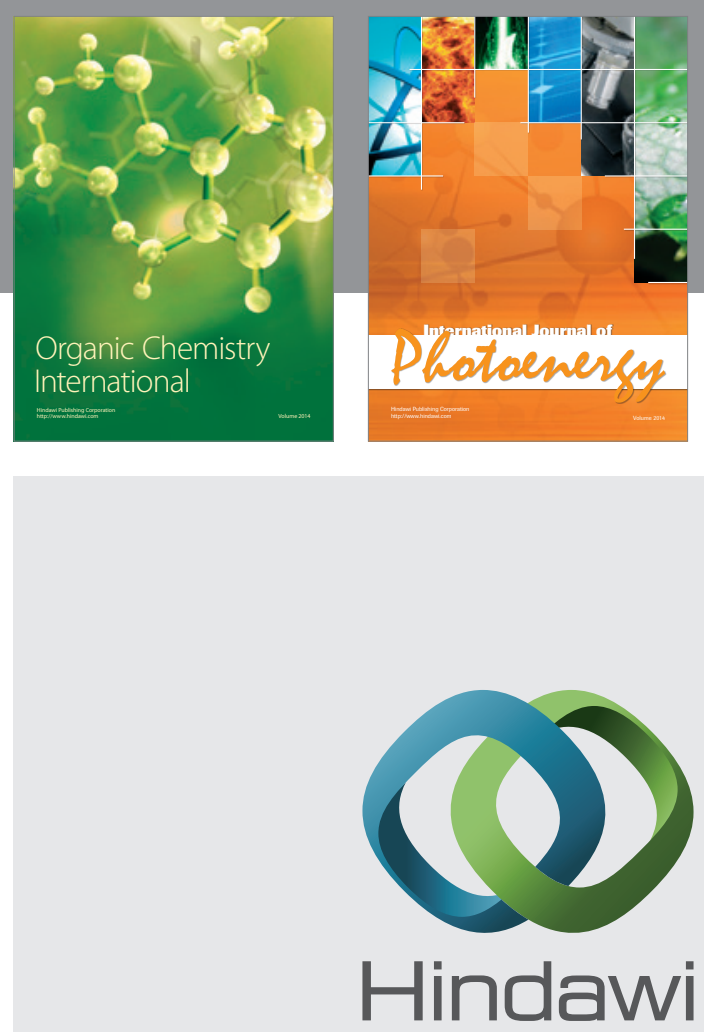

Submit your manuscripts at

http://www.hindawi.com

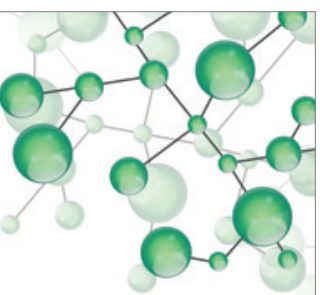

International Journal of

Inorganic Chemistry

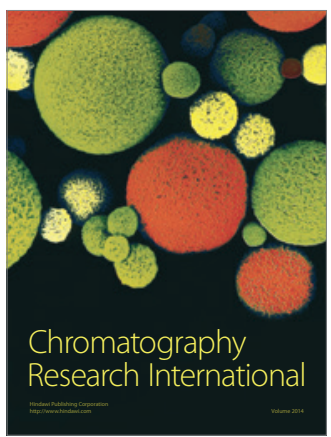

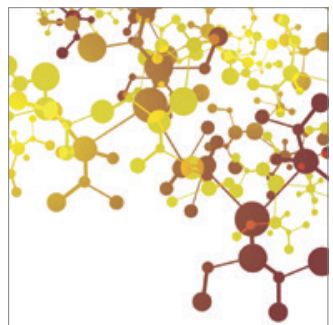

Applied Chemistry
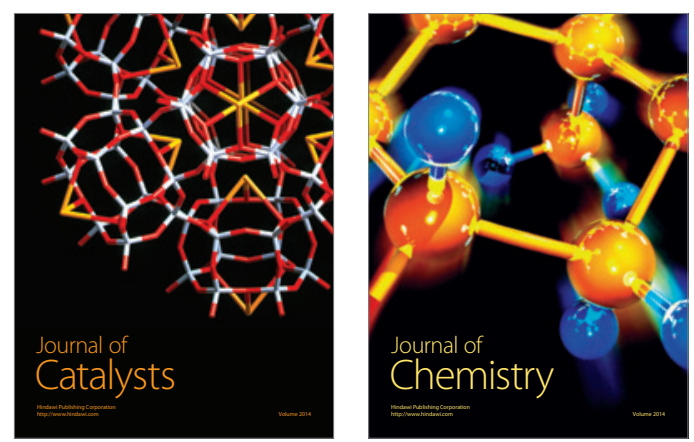
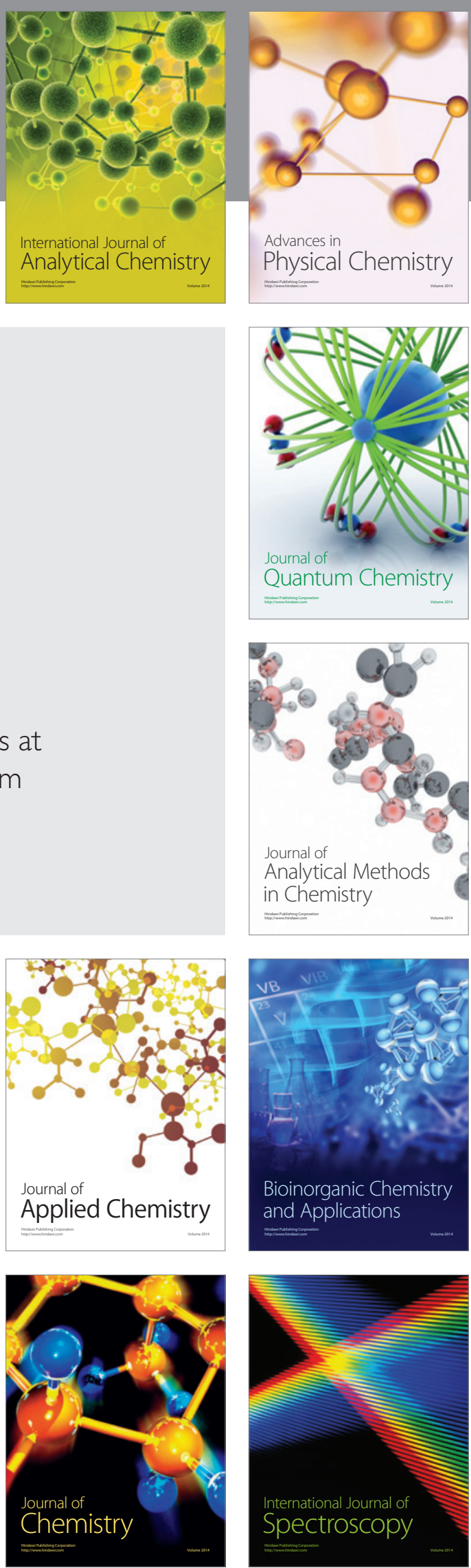